\title{
Carvedilol Phosphate Extended-Release Capsule
}

National Cancer Institute

\section{Source}

National Cancer Institute. Carvedilol Phosphate Extended-Release Capsule. NCI

Thesaurus. Code C88298.

An extended-release capsule formulation containing the phosphate salt of carvedilol, a nonselective beta-adrenergic blocking agent with alpha 1-adrenergic blocking activity. Carvedilol is a racemic mixture; the S(-) enantiomer non-selectively binds to and blocks beta-adrenergic receptors, exerting negative inotropic and chronotropic effects, leading to a reduction in cardiac output. Both $\mathrm{R}(+)$ and $\mathrm{S}(-)$ enantiomers bind to and block alpha 1-adrenergic receptors with equal potency, causing vasodilation and a reduction in peripheral vascular resistance. This agent has no intrinsic sympathomimetic activity. 